\title{
A espiritualidade e o sentido de vida a partir do discurso do sujeito coletivo ateu
}

\author{
The spirituality and the meaning of life from
} the atheist collective subject discourse

\section{Lorena Bandeira Melo de Sá ${ }^{[a]}$, Thiago Antônio Avellar de Aquino ${ }^{[b]^{*}}$}

\author{
[a] Universidade Estadual da Paraíba (UEPB), Campina Grande, PB, Brasil \\ [b] Universidade Federal da Paraíba (UFPB), João Pessoa, PB, Brasil
}

\section{Resumo}

O objetivo deste artigo é averiguar as associações entre espiritualidade e sentido de vida, sob a ótica dos sujeitos ateus. Parte-se da concepção de que a espiritualidade atua como importante fator protetivo do sujeito, direcionando-o a uma busca de sentido para sua vida e que independe de prática religiosa. Tal concepção baseia-se no aporte teórico da abordagem psicológica da Logoterapia e Análise Existencial. Trata-se de uma pesquisa metodológica qualitativa, em que a amostra foi de 18 sujeitos, a fim de evidenciar, através do discurso dos ateus, conceitos sobre espiritualidade e sentido

LBMS: MSc in religions cience, e-mail: lobandeira@hotmail.com

TAAA: PhD in Social psicology, e-mail: logosvitae@ig.com.br 
de vida e suas relações. Foi realizada uma entrevista semi-estruturada contendo as seguintes perguntas "como você definiria espiritualidade" "como você definiria sentido de vida?" "para você, o que seriam manifestações/expressões de espiritualidade?" “qual a relação que você percebe entre espiritualidade e sentido de vida?”, que foram analisadas a partir do Discurso do Sujeito Coletivo (DSC) para análise de dados qualitativos. 0 estudo evidencia que os participantes percebem espiritualidade, em sua maioria, como sendo um tipo de crença ou conexão com algo ou alguém; sentido de vida como sendo, principalmente, um objetivo ou motivação pessoal ou a atribuição que o sujeito dá de forma significativa a algo e não percebe relação entre espiritualidade e sentido de vida.

Palavras-chave: Sentido de vida. Espiritualidade. Ateus.

\section{Abstract}

The objective of this article to examine the associations between spirituality and meaning of life, from the perspective of atheists. It starts with the idea that spirituality acts as an important protective factor of the subject, directing you to a search for meaning for their lives and that is independent of religious practice. This conception is based on the theoretical framework of the psychological approach to Logotherapy and Existential Analysis. This is a methodological research qualitative, in which the sample was 18 subjects, in order to show, through the speech of the atheists, concepts of spirituality and meaning of life and their relationships. a semi-structured interview with the following question "how would you define spirituality" was held "how would you define the meaning of life?" "for you, what would be manifestations/ expressions of spirituality?" "What is the relationship that you see between spirituality and meaning of life?" which were analyzed from the Collective Subject Discourse (CSD) for the analysis of qualitative data. The study showed that the participants perceive spirituality, mostly as a kind of belief or connection with something or someone; sense of life as being primarily an objective or personal motivation or assignment that the subject gives significantly to something and does not realize the relationship between spirituality and meaning of life.

Keywords: Meaning of life. Spirituality. Atheists. 


\section{Introdução}

“Não é por ser ateu que vou castrar a minha alma! O espírito é uma coisa importante demais para ser abandonado aos padres, aos mulás ou aos espiritualistas. É a parte mais elevada do homem, ou antes, sua função mais elevada, que faz de nós outra coisa que um bicho, mais e melhor do que os animais que também somos" (COMTE-SPONVILLE, 2009, p. 127).

O presente manuscrito parte dessa mesma concepção apresentada por Comte-Sponville (2009), a qual concebe a espiritualidade como uma dimensão humana. Ademais, tendo em conta a escassez de pesquisas com o coletivo de ateu, considera-se importante constituir um conjunto de pesquisa que possa ampliar e contribuir com o campo de pesquisa da psicologia do ateísmo. Nessa perspectiva, elencou-se a espiritualidade por considerá-la um ponto nodal entre o teista e o ateísta.

\section{Espiritualidade}

A espiritualidade apresenta grande variação conceitual e comumente se confunde com os conceitos de religiosidade e religião (PANZINI et al, 2007). Koenig (2012) a define, como sendo a busca de cada sujeito por um propósito, um sentido para sua vida, sendo, essa busca, inerente ao ser humano, que pode ser encontrado através da relação do homem com o transcendental, seja o divino, a natureza, a arte, as relações sociais (Koenig, 2012). Dessa forma, um ateu poderia possuir uma espiritualidade genuína.

Comte-Sponville (2007) assevera que a espiritualidade está mais relacionada às experiências do que ao domínio do pensamento, estando, assim, mais voltada para a libertação, plenitude e serenidade. Koenig (2012), por sua vez, postula a espiritualidade enquanto parte da experiência humana que possui aspectos cognitivos (a partir da busca de sentido e crenças), experienciais (sentimentos positivos como esperança, amor, valores, relações e conexões) e comportamentais (manifestação de crenças espirituais e estado espiritual interno). 
Segundo Vaillant (2010), a espiritualidade humana corresponde às experiências psicológicas relacionadas à ideia de conexão entre o ser humano e o transcendente. Conforme pensa, a espiritualidade seria uma experiência mais emocional, enquanto que a religião, mais cognitiva. Nesse sentido, ateus e agnósticos também possuem fé, já que a ausência de fé resulta no niilismo e, não, no ateísmo (VAILLANT, 2010).

\section{Vontade de sentido e sentido de vida}

A vontade de sentido expressa a motivação primordial do ser humano, rompendo com a ideia de prazer ou felicidade enquanto volição do ser humano, mas sim, o motivo que o leva à felicidade ou proporciona essa felicidade, como consequência de uma ação dotada de sentido. Para Frankl (2011), antropologicamente, o ser humano sempre se direciona a algo além dele a fim de alcançar a autotranscendência, num processo originado pela tensão que direciona essa pessoa à relação com o mundo, caracterizando a abertura do ser humano em contrapartida à ideia de um ser fechado em si mesmo.

Na perspectiva frankliana, são os valores que direcionam a pessoa ao encontro do sentido, seja através de algo que ele contribui ao mundo, em um trabalho (valores criativos), ou nas relações que o ser humano estabelece com as pessoas e o mundo (valores experienciais) ou a partir do posicionamento que o sujeito toma em situações limite (valores atitudinais) (AQUINO, 2013).

Tanto os valores como a vontade de sentido são expressos a partir de uma terceira dimensão do ser humano, noética ou espiritual, além das dimensões biológica e psicológica. Nessa perspectiva, o ser humano deve ser visto de tal forma, sem ignorar todas as dimensões que compõem o ser. O acesso ao espiritual dá-se a partir da expressão dos fenômenos especificamente humanos, os quais Ortíz (2012) denomina recursos noológicos, características antropológicas de potencialidades do ser humano que contribuem para o processo de autodistanciamento e autotranscendência. 
É na dimensão noética em que se localiza a religiosidade inconsciente, a fé, os valores e a vontade de sentido do ser humano. A partir do postulado de que essa dimensão é sadia, caracterizando o aspecto resiliente do ser, ainda assim existem situações em que há uma inacessibilidade da dimensão noética, podendo caracterizar atitudes inautênticas do homem, um vazio existencial ou neurose noogênica (FRANKL, 2007).

\section{0 ateísmo para a Logoterapia}

A Logoterapia e Análise Existencial foi constituída por Viktor Emil Frankl enquanto proposta teórica e abordagem psicoterapêutica a partir da compreensão do homem como um ser dotado de uma dimensão denominada noética/espiritual e, a partir da perspectiva fenomenológica-existencial, Frankl (2007) desenvolve seus conceitos fundamentais, dentre eles a ideia de uma dimensão espiritual, motivada pela vontade de sentido a partir da realização de valores.

Frankl e Lapide (2013) caracterizam o ateu como sendo alguém que obedece à sua consciência (Gewissen) enquanto instância última, ignorando a sua transcendência. Já os sujeitos religiosos atribuem sua consciência a deus, enquanto voz (FRANKL, 2007).

Frankl e Lapide (2013) agrupam os ateus em três categorias, a partir de suas posturas: os anticlericaisse revoltam contra deus, culpando-o pelos males percebidos na terra e com os que o representam.O pseudoateu, que tem um histórico de imposição religiosa e, assim, irritam-se com deus.Os antiteístas, que não podem ser vistos como ateus, uma vez que travam lutas contra deus. $\mathrm{O}$ ateísmo, segundo os autores, não possui o direcionamento vertical, no caso, para uma divindade. Concluem que o ateísmo verdadeiro perpassa pela tolerância, expressando valores que transcendem a partir do noético (FRANKL e LAPIDE, 2013). 


\section{Espiritualidade e ateísmo}

No que tange à espiritualidade ateia, seu desenvolvimento dá-se no período industrial. De acordo com Freixes (2014), nos últimos anos, houve um novo aspecto cultural que ressaltou o sentimento ao invés da doutrina, em que a experiência direta com o sagrado é mais valiosa do que, necessariamente, um vínculo institucional. Isso se deu por uma maior consolidação do individualismo expressivo e fortaleceu as discussões que se tem sobre religiosidade. Esse sentimento de experiência pessoal com o sagrado reflete o aumento dos chamados sem religião. Essa categoria contempla ateus, agnósticos e sujeitos que abandonaram instituições religiões, mas que ainda se declaram crentes no tocante a alguma divindade.

De acordo com Comte-Sponville (2007), o ateísmo não nega o absoluto, mas nega que ele seja deus. A espiritualidade consiste na fidelidade e na ação, ainda que não direcionada às práticas religiosas. Tratase, portanto, de uma relação social de comunhão e transmissão em que a fidelidade e a ação estão direcionadas às práticas sociais a partir da expressão de emoções positivas.

A espiritualidade ateia é crítica, mas não no sentido negativo, no entanto, está pautada na razão e, principalmente nas relações com a ciência. Assim, tanto a espiritualidade laica de tradição confessional, ou seja, a espiritualidade daqueles que denominam-se religiosos, quanto a espiritualidade ateia, ou seja, daqueles que se denominam ateus, possuem em comum a percepção da relevância que ela possui na qualidade de vida do homem, sendo uma experiência real, de transformação da realidade (COMTE-SPONVILLE, 2007).Tendo em conta as considerações supracitadas, o objetivo do presente artigo é identificar os conceitos de espiritualidade e sentido da vida a partir do discurso do sujeito coletivo ateu. Para tanto, realizou-se uma pesquisa empírica, o que é descrita a seguir. 


\section{Metodologia}

\section{Participantes}

Participaram desse estudo 18 sujeitos ateus, maiores de 18 anos, com média de idade de 30 anos, sendo 16 do sexo masculino e 2 do sexo feminino. Dentre os participantes, 13 possuíam ensino superior completo, 3 possuíam o superior incompleto, 1 ensino fundamental completo e 1 ensino médio completo. Com relação ao estado civil, dois eram casados e 16 solteiros. A amostra da pesquisa foi definida por conveniência. A pesquisa teve como critério de inclusão os participantes que se declarassem ateus.

\section{Instrumentos de coleta de dados}

O instrumento constou de duas partes, descritas a seguir:

a) Entrevista semi-estruturada. Consistida de quatro perguntas: "como você definiria espiritualidade?", “como você definiria sentido de vida?"; "para você, o que seriam manifestações de espiritualidade?"; "qual a relação que você percebe entre espiritualidade e sentido de vida?"

b) Questionário sócio-demográfico. Contou com questões acerca da idade, sexo, nível de escolaridade e estado civil. Uma vez que a pesquisa era especificamente para ateus, não foi questionada a religião dos participantes.

\section{Procedimento para coleta de dados}

A coleta ocorreu durante o Encontro da Nova Consciência, evento realizado há mais de 20 anos na cidade de Campina Grande, durante o Carnaval, com a proposta de diálogo inter-religioso, cultura de paz, desenvolvimento sustentável e inclusão racional. Dentro do Encontro da Nova Consciência ocorre o Encontro de Ateus e Agnósticos, onde foi realizada a coleta da pesquisa. Além disso, outros sujeitos que não fizeram parte do encontro supracitado participaram da pesquisa, a partir de divulgação e convite da própria pesquisadora. 
A coleta foi realizada entre os meses de fevereiro a abril de 2015 e os dados foram coletados de forma individual, por meio de gravação em áudio com autorização dos participantes. As entrevistas tiveram tempo médio de cinco minutos, sendo transcritas posteriormente para fins de análise.

\section{Procedimento para análise dos dados}

A análise dos dados foi realizada através do Discurso do Sujeito Coletivo (DSC), que é uma técnica metodológica qualitativa desenvolvida por Lefevre e Lefevre na década de 1990 e propõe a expressão ou opinião do pensamento coletivo, trabalhando com significados, motivos, crenças, valores e atitudes dos sujeitos participantes (GONDIM e FISCHER, 2009).

De acordo com Lefevre, Lefevre e Marques (2009), a elaboração de um discurso síntese é feita por agrupamento de semelhança semântica dos discursos, a partir de seleção de conteúdo, sentido manifestado e/ou latente no discurso e edição do discurso a partir de pensamento coletivo. Tal elaboração se justifica pelos conceitos de expressões-chave (literalmente transcritos), ideias centrais (sentido dos depoimentos) e o discurso do sujeito coletivo (LEFÈVRE e LEFÈVRE, 2005).

Para corroborar a análise de dados desse estudo, três juízes foram convidados a analisar as categorias elaboradas pela pesquisadora responsável do estudo, obtendo $100 \%$ de concordância entre as classificações semânticas das categorias.

\section{Considerações éticas}

Este estudo foi aprovado pelo Comitê de Ética da Universidade Federal da Paraíba, protocolo número 37231714.7.0000.5188, seguindo as prescrições da Resolução 466/12, do Conselho Nacional de Saúde (Ministério da Saúde).

Os participantes foram informados previamente acerca dos objetivos da pesquisa e de que todas as informações seriam mantidas em sigilo, bem como foram comunicados da possibilidade de abandono de participação da pesquisa por parte deles. Por fim, a assinatura de Termo de Consentimento Livre e Esclarecido foi efetuada, antes do início da pesquisa. 


\section{Resultados e discussão}

As respostas dos sujeitos permitiram o agrupamento em ideias centrais dos discursos coletivos. Entretanto, algumas respostas fugiam da temática da pergunta ou os participantes não responderam a pergunta, o que justifica o fato de que as tabelas não apresentarem percentual total de frequencia de $100 \%$.

A primeira pergunta realizada, "como você definiria espiritualidade?”, teve maior frequencia de 05 ideias centrais, sendo tipo de crença e conexão com algo/alguém com freqüência de $16,6 \%$, seguida das ideias de autoconhecimento, criação humana e motivação, que obtiveram menor frequencia, conforme Tabela 1.

Tabela 1 - Expressões-chave e ideias centrais acerca do conceito de manifestações/ expressões de espiritualidade para ateus

\begin{tabular}{|c|c|c|c|}
\hline Sujeito & Expressões-chave & Ideias centrais & Frequência \\
\hline 01 & "crer em algo, em alguma coisa ou alguém" & \multirow{3}{*}{ Tipo de crença } & \multirow[b]{3}{*}{$16,6 \%$} \\
\hline 06 & $\begin{array}{l}\text { "tipo de crença que você tem que tá ligado a } \\
\text { algum fator sobrenatural" }\end{array}$ & & \\
\hline 12 & $\begin{array}{l}\text { "seria alguma pessoa que tem fé em alguma } \\
\text { coisa além desse estereótipo de deus" }\end{array}$ & & \\
\hline 11 & $\begin{array}{l}\text { "é você sentir como se você faz parte de algo } \\
\text { que é maior do que você" }\end{array}$ & \multirow{3}{*}{$\begin{array}{l}\text { Conexão com algo } \\
\text { ou alguém }\end{array}$} & \multirow{3}{*}{$16,6 \%$} \\
\hline 13 & $\begin{array}{l}\text { "você se conectar com outro ser humano, } \\
\text { você se sentir bem a partir das relações } \\
\text { humanas que você tece com outras pessoas" }\end{array}$ & & \\
\hline 16 & "a relação do ser humano com o intangível" & & \\
\hline 07 & $\begin{array}{l}\text { "eu diria autoconhecimento, a gente } \\
\text { se conhecer e conhecer as nossas } \\
\text { possibilidades e limitações e erros" }\end{array}$ & \multirow[t]{2}{*}{ Autoconhecimento } & \multirow[t]{2}{*}{$11,1 \%$} \\
\hline 09 & $\begin{array}{l}\text { "forma como o indivíduo se entende como } \\
\text { existente no mundo" }\end{array}$ & & \\
\hline 15 & $\begin{array}{l}\text { "algo criado para relacionar a espíritos e } \\
\text { espiritismo" }\end{array}$ & \multirow[t]{2}{*}{ Criação humana } & \multirow[t]{2}{*}{$11,1 \%$} \\
\hline 17 & “é algo que o ser humano criou” & & \\
\hline 08 & $\begin{array}{l}\text { "ação que você tem pra Ihe manter vivo; } \\
\text { aquilo que você faz que Ihe dá vontade de } \\
\text { continuar dia após dia" }\end{array}$ & Motivação & $5,5 \%$ \\
\hline
\end{tabular}

Fonte: elaborado pelos autores. 
A ideia central mais frequente a ser expressa que o conceito de espiritualidade está relacionado a um tipo de crença, seja relacionada à crença em algo ou alguém, como ilustrado no discurso 01. A ideia de que crença está relacionada a algo além de uma divindade pode ser evidenciada no discurso 06 e 12.

As respostas dos sujeitos nessa categoria relacionam-se com os conceitos de Koenig (2012), principalmente, sobre o conceito de espiritualidade, estando voltado para uma crença que, não necessariamente, estará relacionada à religião, podendo estar voltado à experiência humana com o transcendental, indo, portanto, além de um estereótipo de deus, ou voltado ao aspecto sobrenatural.

Dessa forma, pode-se construir o discurso do sujeito coletivo a partir da ideia central da categoria tipo de crença da seguinte forma: Espiritualidade é "crer em algo, em alguma coisa ou alguém, que tá ligado a algum fator sobrenatural ou alguma coisa além desse estereótipo de deus." (SIC)

A segunda categoria mais frequente de respostas contempla a ideia de que espiritualidade relaciona-se com a conexão do homem com algo ou com alguém. As ideias de pertença, do estabelecimento de relação social do homem com outro ser, estão expressas nos discursos dos sujeitos 11 e 13 .

Koenig (2012) aponta a espiritualidade enquanto experiência relacional do sujeito, assim como Comte-Sponville (2007), que ressaltam o caráter comportamental do sujeito a partir das suas relações sociais, enquanto expressão da espiritualidade. Vaillant (2010) aponta, ainda, a relação que o homem teria com o absoluto, o transcendental, o que direciona ao discurso do sujeito 16 , que coloca a relação do homem com o intangível, ali também, podendo estar contemplada a ideia de espiritualidade.

Dessa forma, o discurso do sujeito coletivo da ideia central conexão com algo/alguém, foi constituída da seguinte forma:

Espiritualidade é "você se conectar com outro ser humano e sentir como se você faz parte de algo que é maior do que você" (SIC).

Os discursos que expressam a ideia de autoconhecimento, a ser o fato de o homem conhecer a si mesmo (discurso do sujeito 07) e 
entender-se enquanto ser no mundo (discurso do sujeito 09) relaciona-se ao conceito de autocompreensão, teorizado por Ortíz (2012) a partir do conceito de espiritualidade de Frankl (2007). De acordo com Ortiz (2012) a autocompreensão é a capacidade do sujeito de auto-objetivação de, a partir da compreensão de si mesmo e do mundo com o qual ele se relaciona e perceber sua participação e responsabilidade em sua vida, bem como no mundo.

Dessa forma, o discurso do sujeito coletivo da ideia central autoconhecimento, expressa-se da seguinte forma:

Espiritualidade é "forma como o indivíduo se entende como existente no mundo, a gente se conhecer e conhecer as nossas possibilidades e limitações e erros" (SIC).

A ideia da espiritualidade como criação foi constatada como a quarta ideia central de maior frequencia discursiva. De forma geral, o ateísmo nega a existência de uma realidade transcendente regida por uma ordem mágica o que se coaduna com o discurso dos sujeitos 15 e 17 ao pontuarem sobre o aspecto de espiritualidade ser criação do homem.

O discurso do sujeito coletivo da ideia de criação do homem, expressa-se, da seguinte forma:

Espiritualidade é "é algo que o ser humano criou para relacionar a espíritos e espiritismo" (SIC).

O discurso que contempla a ideia de motivação, expresso pelo discurso do sujeito 08, caracteriza a busca de um propósito nas ações do homem como conceito de espiritualidade. Koenig (2012) define espiritualidade enquanto busca por um propósito de existência, sendo inerente ao homem. Comte-Sponville (2007) corrobora com esse postulado, apontando para a motivação do sujeito em significar sua existência, enquanto definição de espiritualidade.

A segunda pergunta do questionário da pesquisa, "como você definiria sentido de vida?", teve maior frequencia de três ideias centrais, sendo objetivo/motivação pessoal com maior freqüência de $27,7 \%$, seguida das ideias de atribuição de sentido e sentido biológico que obtiveram menor frequencia, conforme Tabela 2. 
Tabela 2 - Expressões-chave e ideias centrais acerca do conceito de sentido de vida para ateus

\begin{tabular}{|c|c|c|c|}
\hline Sujeito & Expressões-chave & $\begin{array}{l}\text { Ideias } \\
\text { centrais }\end{array}$ & Frequencia \\
\hline 05 & $\begin{array}{l}\text { "a motivação que o indivíduo tem para consigo } \\
\text { mesmo e para um projeto interior que tem para } \\
\text { consigo mesmo a partir de suas escolhas" }\end{array}$ & \multirow{5}{*}{$\begin{array}{l}\text { Objetivo/ } \\
\text { motivação } \\
\text { pessoal }\end{array}$} & \multirow{5}{*}{$27,7 \%$} \\
\hline 06 & $\begin{array}{l}\text { "algum objetivo de acordo com suas crenças e que } \\
\text { você toma como uma meta" }\end{array}$ & & \\
\hline 09 & $\begin{array}{l}\text { "é um objetivo que você tem no seu tempo de } \\
\text { existência, tentar contribuir ao máximo com o } \\
\text { mundo" }\end{array}$ & & \\
\hline 14 & $\begin{array}{l}\text { "uma pessoa poder trabalhar, um foco em alguma } \\
\text { coisa, que possa te dar dinheiro, paz, é isso" }\end{array}$ & & \\
\hline 16 & $\begin{array}{l}\text { "eu acredito que o sentido da vida vai depender } \\
\text { de cada pessoa, o que ela atribui para si, dar } \\
\text { significado a sua vida a partir do que você aspira" }\end{array}$ & & \\
\hline 02 & $\begin{array}{l}\text { "eu acredito que somos nós que damos sentido à } \\
\text { vida" }\end{array}$ & \multirow{4}{*}{$\begin{array}{l}\text { Atribuição de } \\
\text { sentido }\end{array}$} & \multirow{4}{*}{$27,7 \%$} \\
\hline 03 & "é uma coisa que nós damos a nós mesmos" & & \\
\hline 15 & $\begin{array}{l}\text { "aquilo que você tem de fazer, um sentido que você } \\
\text { dá para sua vida" }\end{array}$ & & \\
\hline 18 & $\begin{array}{l}\text { "as escolhas que cada um faz e as consequências } \\
\text { que cada um enfrenta" }\end{array}$ & & \\
\hline 01 & $\begin{array}{l}\text { "pra mim, o sentido natural. Você nascer, viver e } \\
\text { morrer" }\end{array}$ & \multirow{3}{*}{$\begin{array}{l}\text { Sentido } \\
\text { biológico }\end{array}$} & \multirow{3}{*}{$16,6 \%$} \\
\hline 12 & $\begin{array}{l}\text { "é mais uma questão de consequência da teoria da } \\
\text { evolução" }\end{array}$ & & \\
\hline 17 & “é a perpetuação da espécie, fim" & & \\
\hline
\end{tabular}

As respostas que contemplam a ideia central de "objetivo/motivação pessoal" contemplam expressões que dizem respeito à ideia logoterapêutica da vontade de sentido, enquanto motivação primordial do ser humano. De acordo com Pereira (2013), o que o homem verdadeiramente almeja é um motivo para ser feliz, seja através de uma ação que o satisfaz, em relações sociais, sempre que permitam ao sujeito expressar sua identidade.

Especificamente na resposta dos sujeitos 05 e 06 fica clara a ideia de uma motivação, um direcionamento que contribui para a descoberta de um propósito para a sua existência, o que Frankl (2011) define como 
sendo a vontade de sentido. Essa motivação é direcionada a partir dos valores do sujeito, sejam criativos, experienciais ou atitudinais.

O discurso do sujeito 16 relaciona-se à ideia de unicidade do sentido a partir da premissa de que ele, assim como o homem, é único e depende de cada situação, bem como de cada sujeito. Essa relação também pode ser percebida no discurso do sujeito 14, que estabelece o sentido de vida a partir dos valores criativos, ou seja, da relação de um trabalho significativo.

Assim, o discurso do sujeito coletivo da ideia de objetivo/motivação pessoais foi construído da seguinte forma:

Sentido de vida é "a motivação, algum objetivo que o indivíduo tem para consigo mesmo, de acordo com suas crenças, a partir do que você aspira e de suas escolhas" (SIC).

A segunda ideia central extraída dos discursos, "atribuição de sentido" corresponde ao binário liberdade/responsabilidade encontrado na bibliografia logoterápica. A frequencia discursiva de que sentido é algo que damos a nós mesmos, conforme os discursos 02, 03 e 15 demonstram, coadunam com a ideia de que esse sentido é atribuído a partir das escolhas do sujeito, conforme aponta o discurso do sujeito 18.

Assim, o discurso do sujeito coletivo da ideia de atribuição de sentido, expressa-se da seguinte forma:

Sentido de vida "é uma coisa que nós damos a nós mesmos a partir das escolhas que cada um faz e as conseqüencias que cada um enfrenta"(SIC).

A ideia central de sentido biológico, que teve menos freqüência discursiva, contempla expressões condizentes com as ideias da teoria darwinista de evolução, como apontado no discurso do sujeito 12. Os discursos dos sujeitos 01 e 17 correlacionam à ideia do processo natural de existência, biologicamente falando.

Dawkins (2007) aponta ao sentido biológico como importante argumento para a não-existência de deuses, exemplificando especificamente ao processo de seleção natural, proposto por Darwin. Tendo em vista que esse processo é uma realidade, em especial os processos de nascer e morrer, os discursos dos sujeitos que participaram da pesquisa voltam-se para esses processos enquanto significado de nossa existência, ao fato de que o sentido da vida é nascer, viver e morrer. 
O discurso do sujeito coletivo da ideia sentido biológico estabeleceu-se da seguinte maneira:

Sentido de vida é "o sentido natural, conseqüência da teoria da evolução, você nascer, viver e morrer, é a perpetuação da espécie” (SIC).

A terceira pergunta realizada aos participantes, "para você, o que seriam manifestações de espiritualidade?", teve maior frequencia de 03 ideias centrais, sendo expressão psicológica com maior freqüência de 22,2\%, seguida das ideias de ética, formas de interação/vivência transcendental, expressão de sentido e expressão de crenças" que obtiveram menor frequencia, conforme tabela 3 .

Tabela 3 - Expressões-chave e ideias centrais acerca do conceito de manifestações/ expressões de espiritualidade para ateus

\begin{tabular}{|c|c|c|c|}
\hline Sujeito & Expressões-chave & $\begin{array}{l}\text { Ideias } \\
\text { centrais }\end{array}$ & Frequencia \\
\hline 03 & $\begin{array}{l}\text { "experiências religiosas como sendo estados } \\
\text { alterados de consciência" }\end{array}$ & \multirow{3}{*}{$\begin{array}{l}\text { Expressão } \\
\text { psicológica }\end{array}$} & \multirow{3}{*}{$22,2 \%$} \\
\hline 04 & "distúrbios mentais" & & \\
\hline 18 & $\begin{array}{l}\text { "problemas psicológicos de uma pessoa } \\
\text { relacionadas a sua crença num divino" }\end{array}$ & & \\
\hline 02 & $\begin{array}{l}\text { "manifestação da própria natureza humana, } \\
\text { da solidariedade, do bom humor, da boa } \\
\text { convivência" }\end{array}$ & \multirow[t]{2}{*}{$\begin{array}{l}\text { Valores } \\
\text { humanos }\end{array}$} & \multirow[t]{2}{*}{$11,1 \%$} \\
\hline 14 & "ajudar alguém seria uma das coisas" & & \\
\hline 09 & $\begin{array}{l}\text { "a forma como você consegue interagir com esta } \\
\text { dimensão, além do físico }\end{array}$ & \multirow{2}{*}{$\begin{array}{l}\text { Formas de } \\
\text { interação/ } \\
\text { vivência } \\
\text { transcendental }\end{array}$} & \multirow[b]{2}{*}{$11,1 \%$} \\
\hline 10 & $\begin{array}{l}\text { "qualquer tipo de expressão que faça menção } \\
\text { a um tipo de vivência, experiência fora desse } \\
\text { mundo tridimensional" }\end{array}$ & & \\
\hline 08 & "estar fazendo aquilo que eu gosto, um hábito" & \multirow[b]{2}{*}{$\begin{array}{l}\text { Expressões } \\
\text { de sentido }\end{array}$} & \multirow[b]{2}{*}{$11,1 \%$} \\
\hline 16 & $\begin{array}{l}\text { "todas as ações que você pratica a partir daquilo } \\
\text { que você determina enquanto sentido de vida, } \\
\text { da relação com as pessoas, todas as ações } \\
\text { condizentes com aquilo que você acredita que } \\
\text { seja ser humano" }\end{array}$ & & \\
\hline 06 & $\begin{array}{l}\text { "expressar, de alguma maneira, crença que não é } \\
\text { baseada numa coisa científica" }\end{array}$ & $\begin{array}{l}\text { Expressão } \\
\text { de crenças }\end{array}$ & $11,1 \%$ \\
\hline
\end{tabular}


A ideia central mais frequente compreende o conceito de que manifestações de espiritualidade são interpretadas como expressões psicológicas. O que se percebe enquanto maioria discursiva é a expressão patológica da dimensão psicológica, o que pode ser ilustrado nos discursos 04 e 18. Possivelmente, essa atribuição sugere que as manifestações da espiritualidade, por não ser "normal" seriam inautênticas. O discurso do sujeito 03 contempla outro aspecto da expressão psicológica, os estados alterados da consciência, que podem ser percebidos em inúmeras experiências religiosas, como possessão demoníaca, incorporação de entidades, espírito santo.

Assim, o discurso do sujeito coletivo da ideia expressões psicológicas fica assim estabelecido:

Expressões/ manifestações de espiritualidade são "experiências religiosas como sendo estados alterados de consciência, distúrbios mentais de uma pessoa relacionadas a sua crença num divino" (SIC).

A segunda ideia central de maior freqüência contempla a relação entre expressão da espiritualidade com os valores humanos do sujeito, especificamente na demonstração de emoções positivas, como aponta Vaillant (2010). O discurso dos sujeitos 02 e 14 ilustram as emoções da solidariedade, boa convivência, que caracterizam valores que são manifestações da natureza humana.

Comte-Sponville (2007) postula a importância das manifestações valorativas do sujeito, enquanto virtudes, que contribuem para o bom convívio do homem em comunidade.

O discurso do sujeito coletivo da ideia central valores humanos foi construído da seguinte forma:

Expressões/manifestações de espiritualidade são "manifestações da própria natureza humana, como, solidariedade, ajudar alguém, boa convivência" (SIC).

A compreensão de que expressões/manifestações de espiritualidade são formas de o sujeito interagir ou vivenciar o transcendental categoriza-se na terceira ideia central mais frequente. Os termos interação e experiência, apresentados nos discursos dos sujeitos 09 e 10, implicam ações. Essas ações valorativas são expressões da espiritualidade e, enquanto ações transcendentes, seu sentido está além da compreensão 
do homem, caracterizando o que Frankl (2003) denominou de suprassentido.

O discurso do sujeito coletivo da ideia central formas de interação/ vivência com o transcendental estabelece-se conforme colocado abaixo:

Expressões/manifestações da espiritualidade são "qualquer tipo de expressão, experiência fora desse mundo tridimensional, além do físico" (SIC).

Alguns discursos caracterizaram expressões/manifestações de espiritualidade como sendo expressões de sentido, como aponta o discurso do sujeito 16, como sendo ações que caracterizam realizações para o sujeito. Frankl (2003) compreende que a partir da abertura do sujeito, em sua dimensão espiritual, o sujeito estará mais propenso a encontrar um sentido para suas ações. O discurso do sujeito 08 direciona para a realização de ações significativas.

Constatou-se o seguinte discurso do sujeito coletivo para a ideia de expressões de sentido:

Expressões/manifestações de espiritualidade são "todas as ações que você pratica a partir daquilo que você determina enquanto sentido de vida" (SIC).

A ideia central expressões de crenças aponta para o discurso do sujeito 06, que atenta para as expressões/manifestações de espiritualidade estarem direcionadas à crenças dos sujeitos que não necessitam de balizamento científico. Tal discurso relaciona-se com a tese de Vaillant (2010) sobre a fé, enquanto crença, ser uma expressão de espiritualidade que possui caráter intuitivo, não necessitando de uma justificação científica.

Comte-Sponville (2007) corrobora com o posicionamento de que a fé ou a expressão de crença do sujeito é inerente ao mesmo, sendo, portanto, também percebida em ateus, ainda que não seja direcionado a uma divindade.

A quarta e última pergunta realizada aos participantes, "qual a relação que você percebe entre espiritualidade e sentido de vida?", apresentou duas ideias centrais, a de ausência de relação entre sentido de vida e espiritualidade, que teve maior freqüência, com $44,4 \%$, seguida da ideia de presença de relação, com frequencia de 38,8\%, conforme Tabela 4 . 
Tabela 4 - Expressões-chave e ideias centrais acerca da relação entre espiritualidade e sentido de vida para ateus

\begin{tabular}{|c|c|c|c|}
\hline Sujeito & Expressões-chave & $\begin{array}{l}\text { Ideias } \\
\text { centrais }\end{array}$ & Frequencia \\
\hline 03 & $\begin{array}{l}\text { "não tem relação. } 0 \text { sentido não precisa tá } \\
\text { necessariamente ligado à ideia de espiritualidade" }\end{array}$ & \multirow{4}{*}{$\begin{array}{l}\text { Ausência } \\
\text { de relação }\end{array}$} & \multirow{4}{*}{$44,4 \%$} \\
\hline 09 & "na minha concepção, nenhuma” & & \\
\hline 12 & "Nenhuma" & & \\
\hline 16 & "para um conceito religioso, não" & & \\
\hline 05 & $\begin{array}{l}\text { "a espiritualidade pode ser um dos caminhos para } \\
\text { se alcançar sentido de vida" }\end{array}$ & \multirow{4}{*}{$\begin{array}{l}\text { Presença } \\
\text { de relação }\end{array}$} & \multirow{4}{*}{$38,8 \%$} \\
\hline 08 & “eles estão interligados" & & \\
\hline 13 & $\begin{array}{l}\text { "a vida não teria sentido se você não tivesse } \\
\text { espiritualidade, é a soma entre o que você faz, o } \\
\text { que você é, como você perceber e o que você sente } \\
\text { e como você reage às interações com o mundo" }\end{array}$ & & \\
\hline 18 & $\begin{array}{l}\text { "quem tem uma espiritualidade desenvolvida } \\
\text { normalmente atrela valores da espiritualidade a um } \\
\text { sentido de vida" }\end{array}$ & & \\
\hline
\end{tabular}

Os discursos que contemplam a ideia de ausência de relação entre espiritualidade e sentido de vida, pontuam que os dois conceitos não estão ligados entre si, como os discursos dos sujeitos 03, 09 e 12 ou estabelecem algumas prerrogativas, como por exemplo, se estiver relacionado a um contexto religioso, conforme aponta o discurso do sujeito 16.

Autores como Dawkins (2007), Feuerbach (2009) e Onfray (2014) não apontam essa ausência de relação de forma direta, mas pelo seu discurso religioso ou de práticas religiosas ou mesmo místicas, pode-se perceber e relacionar tais conteúdos, também, à religião.

$\mathrm{O}$ que se percebeu durante o contato com os participantes que estabeleceram essa ausência de relação foi uma incongruência discursiva entre os conceitos sobre espiritualidade e sentido de vida que os participantes da pesquisa atribuíram aos conceitos estabelecidos pelos autores das áreas de Ciências das Religiões e Psicologia.

Assim, o discurso do sujeito coletivo da ideia ausência de relação fica estabelecido: 
A relação entre espiritualidade e sentido de vida é "nenhuma. O sentido não precisa tá necessariamente ligado à ideia de espiritualidade” (SIC).

Com relação à segunda ideia central identificada nas respostas dos participantes, a ser presença de relação, percebe-se uma interligação entre ambos os conceitos, como no discurso 08 , bem como uma relação de dependência, conforme discurso do sujeito 13. Os discursos dos sujeitos 05 e 18 expressam o sentido de vida como sendo uma das formas de alcançar um sentido de vida.

O discurso 13 contempla ideias de conexão, pertença e percepção de mundo e que, segundo Frankl (2007) e Comte-Sponville (2007), essa abertura do sujeito contribui para uma maior significação existencial, tendo em vista a expressão de espiritualidade.

O discurso do sujeito 18 reflete sobre a relação entre espiritualidade e sentido de vida a partir dos valores. Tal premissa é defendida por Comte-Sponville (2007) ao apontar que os valores contribuem para o desenvolvimento da espiritualidade e Frankl (2007) complementa ao colocar que os valores direcionam o sujeito à busca de um sentido para a vida. Dessa forma, o discurso do sujeito coletivo da ideia presença de relação foi elaborado na seguinte configuração:

A relação entre espiritualidade e sentido de vida é que "a vida não teria sentido se você não tivesse espiritualidade, estão interligados” (SIC).

Autores como Comte-Sponville (2007), Harris (2015) e Frankl (2007) estabelecem a relação entre espiritualidade e sentido de vida, uma vez que ambos conceitos estão voltados para a busca de um propósito na existência. Dessa forma, o sentido de vida e sua busca são expressões autênticas da espiritualidade.

\section{Considerações finais}

Diante dos resultados acima, percebe-se que o conceito de espiritualidade e sentido de vida coaduna com o dos principais teóricos apontados nesse estudo, sobretudo nos conceitos advindos da logoterapia e a compreensão de espiritualidade de Koenig (2012) e Vaillant (2010). 
O estudo evidenciou que os participantes percebem espiritualidade, em sua maioria, como sendo um tipo de crença ou conexão com algo ou alguém. Já a questão do sentido de vida, compreendem como um objetivo ou motivação pessoal ou a atribuição que o sujeito dá de forma significativa a algo. Quando questionados sobre o que seriam expressões ou manifestações de espiritualidade, a maioria das respostas contemplou a ideia de uma expressão psicológica ou expressão de valores humanos.

Com relação às expressões de espiritualidade, esse ainda é um termo estereotipado, principalmente para a maioria dos entrevistados que assimilou a fenômenos pararreligiosos ou problemas mentais, excluindo uma vastidão de outras formas de expressão da espiritualidade.

A maioria dos participantes não percebe relação entre espiritualidade e sentido de vida. É importante compreender que os sujeitos que compreendem que há uma relação entre tais conceitos, não participavam dos encontros de ateus, expressando uma maior abertura para conceitos filosóficos, metafísicos geralmente encontrados na discussão acerca do sentido da vida e da espiritualidade humana. Em conclusão, recomenda-se que novos estudos possam ser realizados para que o campo de estudos acerca do ateísmo seja mais bem compreendido, não apenas no que tange à espiritualidade, mas também ao que se refere a questão do sentido de vida.

\section{Referências}

AQUINO, T. A. A. Logoterapia e Análise Existencial: uma introdução ao pensamento de Viktor Frankl. São Paulo: Paulus, 2013.

COMTE-SPONVILLE, A. O espírito do ateísmo: introdução a uma espiritualidade sem Deus. São Paulo: Editora Martins Fontes, 2007.

COMTE-SPONVILLE, A. Pequeno tratado das grandes virtudes. São Paulo: Editora Martins Fontes, 2009.

DAWKINS, R. Deus, um delírio. São Paulo: Companhia das Letras, 2007.

FABRY, J. Aplicações práticas da logoterapia. São Paulo: ECE, 1990. 
SÁ, L. B. M.

FEUERBACH, L. Preleções sobre a essência da religião. Petrópolis, RJ: Ed. Vozes, 2009.

FRANKL, V. Psicoterapia e sentido de vida. São Paulo: Ed. Quadrante, 2003.

FRANKL, V. Um sentido para a vida: psicoterapia e humanismo. Aparecida: Ideias e Letras, 2005.

FRANKL, V. A Presença Ignorada de Deus. 13ª ed. São Leopoldo: Editora Sinodal; Petrópolis: Vozes, 2007.

FRANKL, V. A vontade de sentido. São Paulo; Paulus, 2011.

FRANKL, V.; E. LAPIDE, P. A busca de Deus e questionamentos sobre o sentido. Petrópolis: Ed. Vozes, 2013.

FREIXES, F.T. Espiritualidad laica y espiritualidadatea. Horizonte. Belo Horizonte, v. 12, n. 35, p. 716-745, jul./set., 2014.

GIOVANETTI, J. Psicologia Existencial e espiritualidade. In: AMATUZZI, M. M. (Org.) Psicologia e espiritualidade. São Paulo: Paulus, 2005. p.129-146.

GONDIM, S.; FISCHER, T. O discurso, a análise de discurso e a metodologia do discursodo sujeito coletivo na gestão intercultural. In: Revista Cadernos Gestão Social, v.2, n.1, p. 09-26, set./dez., 2009.

HARRIS, S. Despertar: um guia para a espiritualidade sem religião. São Paulo: Companhia das Letras, 2015.

KOENIG, H. Medicina, religião e saúde: O encontro da ciência e da espiritualidade. Porto Alegre: L\&PM Editores, 2012.

KOENIG, H. Religião, espiritualidade e transtornos psicóticos. Revista Psiquiatria Clínica. n.34, supl. 1, p 95- 104, 2007.

LEFÈVRE, F.; LEFÈVRE, A. M. O discurso do sujeito coletivo: um novo enfoque em pesquisa qualitativa (desdobramentos). 2. ed. Caxias do Sul: Educs, 2005.

ONFRAY, M. Tratado de ateologia: física da metafísica. São Paulo: Ed. WMF Martins Fontes, 2014.

ORTÍZ, E. M. El dialogo socrático en la psicoterapia. Bogotá: SAPS, 2012. 
PANZINI, R. et al. Qualidade de vida e espiritualidade. In:Revista de Psiquiatria Clínica, v. 34, n.1, p. 105-115, 2007.

PEREIRA, I. A ética do sentido da vida: fundamentos filosóficos da Logoterapia. Aparecida, SP: Ideias e Letras, 2013.

VAILLANT, G. Fé: Evidências Científicas. Barueri, SP: Manole, 2010.

Recebido: 03/11/2016

Receveid: 11/03/2016

Aprovado: 21/12/2016

Approved: 12/21/2016 
